\title{
Stress-Strain Characteristic of Porous Asphalt Incorporating Cellulose Fiber
}

\author{
Nurul Syazni Othman, Khairil Azman Masri, Ahmad Kamil Arshad, Ramadhansyah Putra Jaya, \\ Mohd Rosli Mohd Hasan
}

\begin{abstract}
Porous asphalt (PA) is a type of asphalt mixture that has large air void content to increase the drainage capability of flexible pavement. However, PA suffers a few drawbacks such as less durable and less tensile strength due to large air void characteristic. Thus, this study intended to utilize cellulose fiber to increase the overall performance of PA. Cellulose fiber (CF) used were in the range of $0.2 \%$ to $0.6 \%$ by weight of $P A$ mixture. Among the tests involve to analyze the overall performance of $C F$ modified PA were Abrasion Loss, Marshall Stability, Resilient Modulus and Dynamic Creep. From data analysis, it shows that 0.4\% CF significantly increased the abrasion resistance. Meanwhile, highest stability and resilient modulus values obtained at $0.6 \%$ CF-PA. From the results, it shows that the addition of CF can significantly enhance the overall performance of PA.
\end{abstract}

Index Terms: Cellulose Fiber; Dynamic Creep; Porous Asphalt; Resilient Modulus; Stability

\section{INTRODUCTION}

Malaysia is a country that having uncertain weather changes such as having heavy rainfall and higher temperature throughout the year. Thus, these phenomena are the main contributor to the problem of asphalt pavement such as rutting and stripping. The damages such as rutting and cracks in asphalt pavement occurred when ambient temperature changed. Rutting will affect the service quality of road due to its poor operational condition. Indeed, it can affect operational safety when it reaches critical depths [1]. Besides that, rainfall will lead to the accident and traffic congestion due to the water ponding above the pavement, which cause the skidding and splashing. Thus, porous asphalt (PA) is one of the solutions used to overcome these problems.

PA is constructing to improve the skid resistance of pavement during rain, reduce splashing effect and produce lower riding noise [2]. These are because the interconnected voids allow the rainwater to be stored and move in the PA mixture. However, the water that tends to flow inside the pavement may cause the ravelling, stability loss and load bearing capacity $[1,2]$. Thus, nowadays there are many study used polymer or fiber as a modified bitumen with different

Revised Manuscript Received on October 22, 2019.

Nurul Syazni Othman, Faculty of Civil Engineering Technology, Universiti Malaysia Pahang, Pahang, Malaysia

Khairil Azman Masri, Faculty of Civil Engineering Technology, Universiti Malaysia Pahang, Pahang, Malaysia

Ahmad Kamil Arshad, Institute for Infrastructure Engineering \& Sustainable Management, Universiti Teknologi MARA, Selangor, Malaysia

Ramadhansyah Putra Jaya, Faculty of Civil Engineering Technology, Universiti Malaysia Pahang, Pahang, Malaysia

Mohd Rosli Mohd Hasan, School of Civil Engineering, Engineering Campus, Universiti Sains Malaysia, Penang, Malaysia characteristics such as good adhesiveness with aggregates, resistance and plastic deformation, and low thermal susceptibility [3].

There are many type of fiber has been used in asphalt mixture such as cellulose fiber (CF), steel fiber (SF), glass fiber (GF), synthetic polymer (SP) and recycle tire fiber (RTF) [4]. The common used as an additive in asphalt mixture as CF. The advantages of fiber are wide availability at low cost, non-hazardous nature low density and well-balanced stiffness, and strength [5].

Thus, the objectives of this study is to evaluate the performance of PA incorporated with CF. The adding of fiber into the asphalt mixture may improve certain properties of PA such as reducing drain down, enhancing the moisture sensitivity and compressive strength in PA. Therefore, this research shows how optimum fiber content performs in asphalt pavement.

\section{MATERIALS AND METHODS}

\section{A. Materials}

The gradation of Porous Asphalt Grading B used for this study as follow Malaysia Specification for Road Works [6]. The total aggregate weight for each sample was approximately $1100 \mathrm{~g}$. The aggregate has been dried and sieved into a selected grading according standard specification PA grading B. The design binder content is adopted from studies by Masri et al. [7]. The type of binder used for this study was PEN 60-70 and cellulose fiber (CF) used as additive material with increment $0.2 \%$ to $0.6 \%$. CF was mixed directly with into asphalt mixture at temperature of $160^{\circ} \mathrm{C}-180^{\circ} \mathrm{C}$. The length of $\mathrm{CF}$ was approximately $2 \mathrm{~cm}$. Table 1 below the aggregate gradation for PA grading $\mathrm{B}$.

Table 1 Aggregate Gradation for PA Grading B

\begin{tabular}{|ccc|}
\hline $\begin{array}{c}\text { Sieve size } \\
(\mathbf{m m})\end{array}$ & \% Passing & \% Retained \\
\hline 14 & 92.5 & 7.5 \\
10 & 65 & 27.5 \\
5 & 17.5 & 47.5 \\
2.36 & 7.5 & 10 \\
0.075 & 3 & 4.5 \\
\hline
\end{tabular}

B. Los Angeles Abrasion Test

Published By: 
Abrasion test was conduct using the Marshall specimens compacted with 50 blows on each side according to ASTM C131. There were 12 samples testing where two sample for $\mathrm{PA}$ without $\mathrm{CF}$ and two samples for each percentage PA with existence CF. Each sample was rotate in steel drum with steel ball with 300 total revolutions and weighed the sample at every 100 revolution. The percentage of abrasion can be calculated by equation 1 :

$$
\% \text { Abrasion }=(\mathrm{W} 1-\mathrm{W} 2) / \mathrm{W} 1 \times 100
$$

Where:

$\mathrm{W} 1$ = average weight of sample before

W2 = average weight of sample after.

\section{Marshall Stability Test}

Stability test was conducted to determine the resistance to plastic flow of cylindrical specimens of asphalt paving mixture loaded in a perpendicular direction to the cylindrical axis. The test conduct using the Marshall specimens compacted with 50 blows on each side according to ASTM D1559. Thus, the stability, density and stiffness were tested with different percentage of CF. The total sample testing for this test were 12 samples where two sample for PA without $\mathrm{CF}$ and two sample for each CF-PC. Every sample was immersed in a water bath for 30 minutes at $60^{\circ} \mathrm{C}$.

\section{Resilient Modulus Test}

The resilient modulus test was used to measure the stiffness modulus of the design asphalt mixtures. In this study, the samples that already compact 50 blows on each side were testing using Universal Testing Machine (UTM) accordance to ASTM D4123. The sample was tested at two different temperatures $\left(25^{\circ} \mathrm{C}\right.$ and $\left.40^{\circ} \mathrm{C}\right)$ with two position and three different pulse repetitions, $1000 \mathrm{~ms}, 2000 \mathrm{~ms}$ and $3000 \mathrm{~ms}$.

\section{E. Dynamic Creep Test}

Dynamic creep test was conducted to determine the rutting potential of asphalt mixture. The samples were testing using Universal Testing Machine (UTM) at temperature $25^{\circ} \mathrm{C}$ with 3600 cycle according to BS EN 12697-25-2013

\section{RESULTS AND DISCUSSION}

\section{A. Los Angeles Abrasion}

Fig. 1 shows the existence of CF in PA sample has lower value of abrasion loss. In general, the lower abrasion loss can enhance the PA performance. These prove that the existence of $\mathrm{CF}$ had improved the abrasion of PA. Before $\mathrm{CF}$ adding into the sample, the abrasion loss for $0 \% \mathrm{CF}$ was $30.99 \%$ after 300 revolutions but after added the $\mathrm{CF}$ into asphalt mixture, the lowest abrasion loss obtained at $0.4 \%$ CF-PA. Fig. 2 shows the abrasion loss for modified PA. It shows at $0.4 \% \mathrm{CF}$ has the lowest abrasion value, $3.13 \%$ while the highest abrasion value was $7.75 \%$ at $0.2 \% \mathrm{CF}$. Thus, it was seen the difference abrasion value when $\mathrm{CF}$ existence in PA (between $0 \% \mathrm{CF}$ and $0.4 \% \mathrm{CF}$ ) was $27.86 \%$.

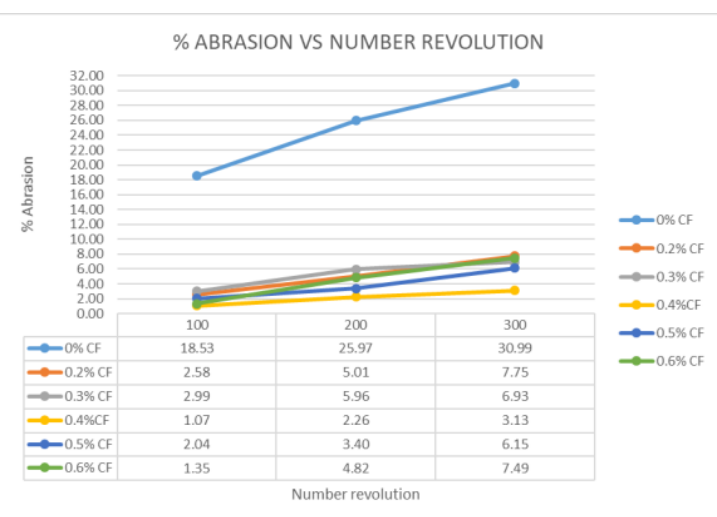

Fig. 1 Abrasion Loss Value for Unmodified PA

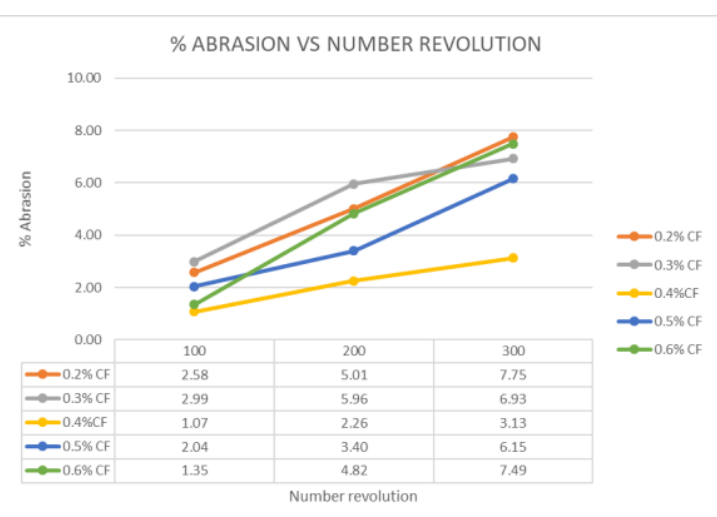

Fig. 2 Abrasion Loss Value for Modified CF-PA

\section{B. Volumetric Properties}

Fig. 3 shows the density of unmodified sample and modified CF-PA. Density is defining as mass per unit volume. The highest density happened at $0.6 \% \mathrm{CF}$ while lowest at $0 \% \mathrm{CF}$. In general, the increasing density of pavement will be increasing the fatigue life, rutting resistance and durability. However, the result not slightly increasing when existence $\mathrm{CF}$ was added into the asphalt mix.

The results presented in Fig. 4 illustrate the average stability of two samples for unmodified PA and modified CF-PA. Stability is means the maximum load applied before failure happen. From the Figure 4, at the $0.6 \%$ CF-PA, the stability value was highest value, 6732 Newton compared to another modified CF-PA while unmodified PA was the lowest stability, 3950.5 Newton. In general, the stability of pavement influenced by density. Thus, the highest density was giving more stability of sample.

Based on the Fig. 5, the result shows the relationship between stiffness and percentage of $\mathrm{CF}$ content. From the graph, the higher stiffness was at the $0.4 \% \mathrm{CF}$ while the lowest stiffness was at the $0 \% \mathrm{CF}$. Thus, the higher stiffness was leads to higher strength of pavement. However, the stiffness should be at optimum due to the brittleness will take place thus lead to cracking. 


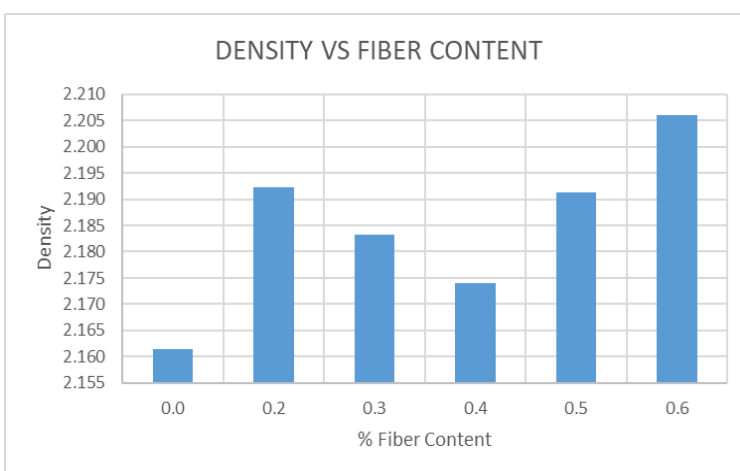

Fig. 3 Density of CF-PA

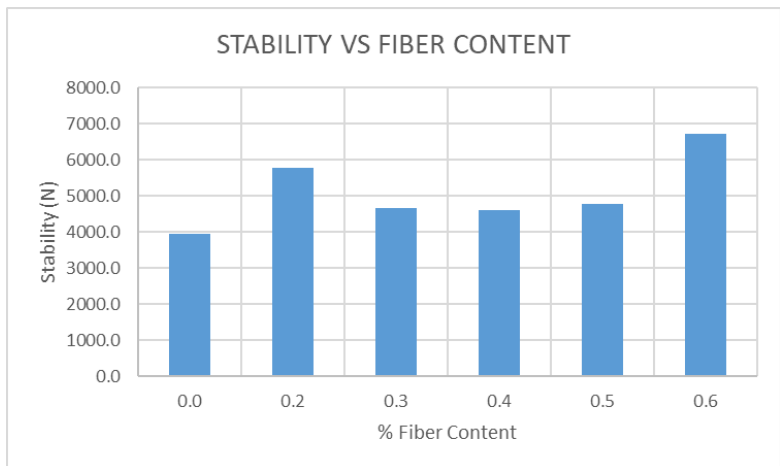

Fig. 4 Stability of CF-PA

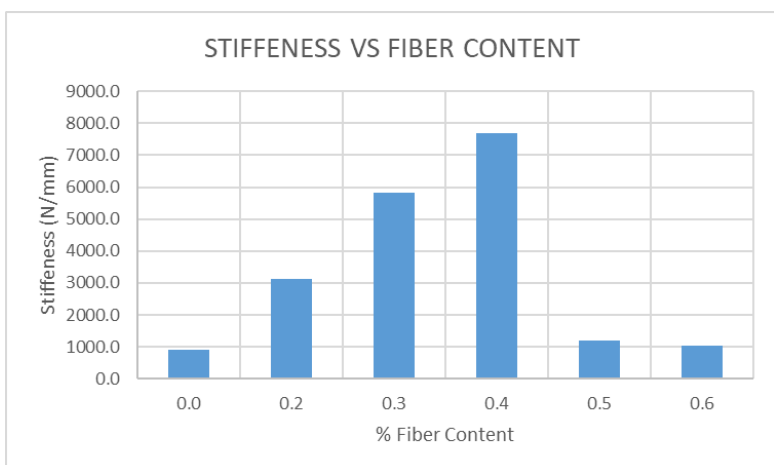

Fig. 5 Stiffness of CF-PA

\section{Resilient Modulus}

Based on the Fig. 6, the result shows that the higher pulse repetitive period loads, the lower the resilient modulus value. At the $1000 \mathrm{~ms}$ pulse period, the highest resilient value obtained at $0.6 \%$ CF-PA was $1988 \mathrm{MPa}$ while for 0\% CF-PA was $1865 \mathrm{MPa}$. From Fig. 7, the highest resilient modulus was $974 \mathrm{MPa}$ at $1000 \mathrm{~ms}$ pulse repetition and the lowest was 744 $\mathrm{MPa}$ at $0.2 \% \mathrm{CF}-\mathrm{PA}$. From the both figure, it can see that the result at different pulse repetition was not show in uniform trend. Thus, the existence of CF in PA was not give impact towards resilient modulus value [7]. This finding is contradicted with a study by Masri et al. [8], where the utilization of nanosilica enhanced the properties of porous asphalt.

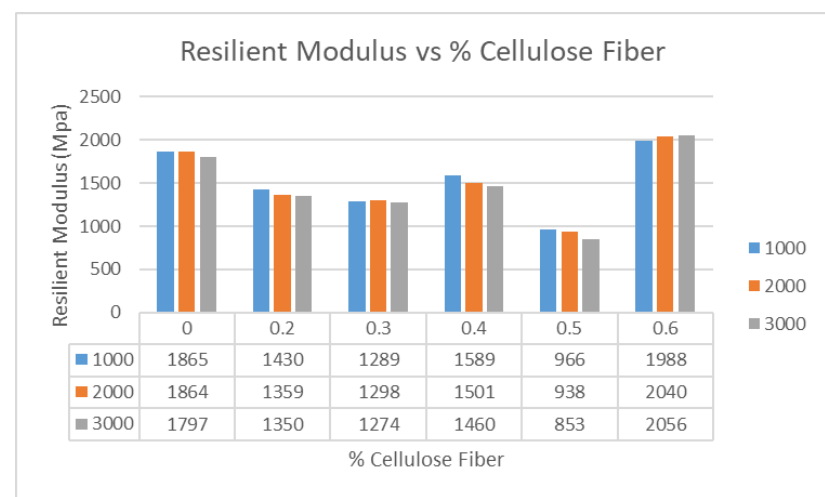

Fig. 6 Resilient Modulus of CF-PA at $25^{\circ} \mathrm{C}$

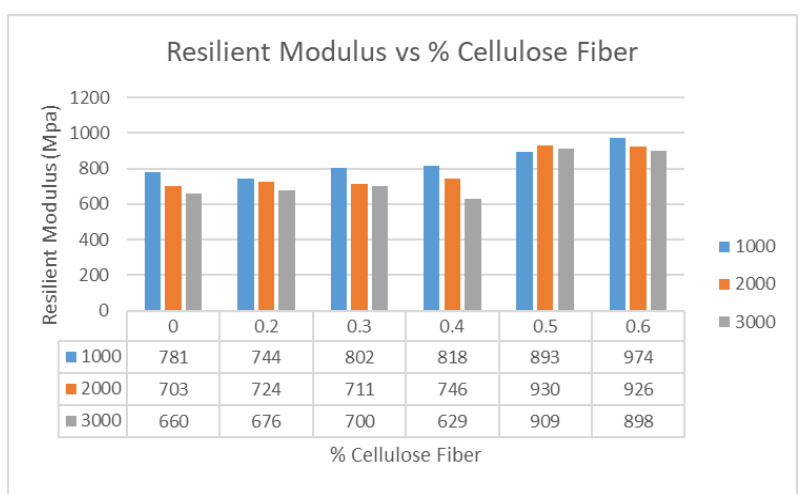

Fig. 7 Resilient Modulus of CF-PA at $40^{\circ} \mathrm{C}$

\section{Dynamic Creep}

Based on the Fig. 8, it shows the relationship between the cycle and strain for unmodified and modified samples at temperature $25^{\circ} \mathrm{C}$. From that graph, it can see that some of the percentage of $\mathrm{CF}$ cannot give better impact to PA towards dynamic creep value but at the $0.2 \%, 0.4 \%$ and $0.5 \% \mathrm{CF}$ content shows the improvement of PA performance. Thus, between three different percentages $\mathrm{CF}$ content, at $0.2 \% \mathrm{CF}$ content was better performance compared than unmodified and another modified sample. Table 2 summarizes the value of creep modulus for each fiber content. The result is consistent with a study by Arshad et al. [9], where the addition of nanoparticles improves the stiffness of modified asphalt mixtures $[10,11]$.

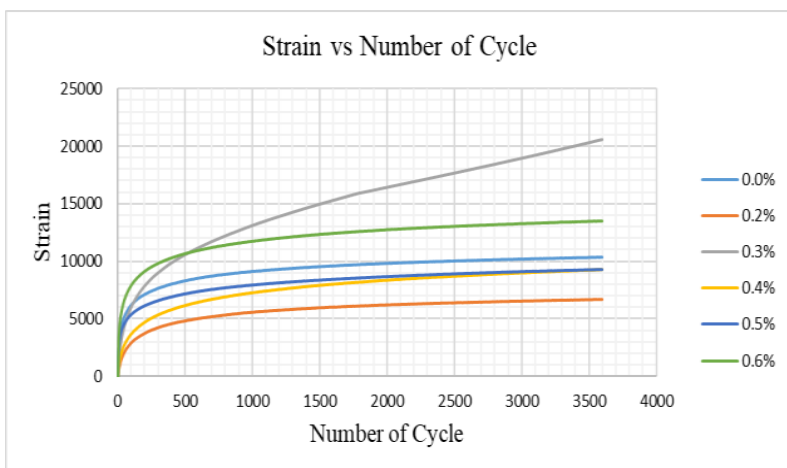

Fig. 8 Dynamic Creep at $25^{\circ}$ 
Table 2 Creep Modulus at $25^{\circ}$

\begin{tabular}{cc}
\hline Cellulose Fiber Content (\%) & $\begin{array}{c}\text { Creep Modulus } \\
(\mathbf{M P a})\end{array}$ \\
\hline 0.0 & 10.40 \\
0.2 & 6.66 \\
0.3 & 20.58 \\
0.4 & 9.30 \\
0.5 & 9.32 \\
0.6 & 13.51 \\
\hline
\end{tabular}

\section{E. Optimum Fiber Content}

Table 3 shows the ranking of performance PA at every laboratory test conducted to determine the optimum fiber content. The excellent ranking was describing by "1" while the worse was " 6 ". The lowest total performance was being the optimum fiber content. Thus, $0.6 \% \mathrm{CF}$ was the optimum fiber content due to its performance in abrasion, stability and resilient modulus were better than other percentage $\mathrm{CF}$ content.

Table 3 Ranking of Performance Tests

\begin{tabular}{lcccccc}
\hline \multicolumn{1}{c}{ Test } & $\mathbf{0 \%}$ & $\mathbf{0 . 2 \%}$ & $\mathbf{0 . 3 \%}$ & $\mathbf{0 . 4 \%}$ & $\mathbf{0 . 5 \%}$ & $\mathbf{0 . 6 \%}$ \\
& $\mathbf{C F}$ & $\mathbf{C F}$ & $\mathbf{C F}$ & $\mathbf{C F}$ & $\mathbf{C F}$ & $\mathbf{C F}$ \\
\hline LAA & 6 & 5 & 3 & 1 & 2 & 4 \\
Density & 6 & 2 & 4 & 5 & 3 & 1 \\
Stability & 6 & 2 & 4 & 5 & 3 & 1 \\
Stiffness & 4 & 3 & 2 & 1 & 5 & 6 \\
RM & 2 & 4 & 5 & 3 & 6 & 1 \\
$\left(25^{\circ} \mathrm{C}\right)$ & 5 & 6 & 4 & 3 & 2 & 1 \\
RM & 4 & 1 & 6 & 2 & 4 & 5 \\
$\left(40^{\circ} \mathrm{C}\right)$ & & & & & & \\
Dc & & & & & & \\
Total & $\mathbf{3 3}$ & $\mathbf{2 3}$ & $\mathbf{2 8}$ & $\mathbf{2 0}$ & $\mathbf{2 4}$ & $\mathbf{1 9}$ \\
\hline
\end{tabular}

$* 1=$ Excellent, $2=$ Very good, $3=$ Good, $4=$ Moderate, $5=$ Poor, $6=$ Very poor

\section{CONCLUSION}

From this study, the cellulose fiber $(\mathrm{CF})$ is capable to improve the performance of porous asphalt (PA). Among the conclusion are:

- For LA abrasion value, the addition CF is significantly reduced the abrasion loss for all proportion of fibers compared to unmodified PA.

- From Marshall Stability test, the value of stability is the highest at $0.6 \% \mathrm{CF}$ content.

- From the result of resilient modulus, the addition of $\mathrm{CF}$ in PA does not shows any change between unmodified PA and modified CF-PA in the resilient modulus at the both temperature $\left(25^{\circ} \mathrm{C}\right.$ and $\left.40^{\circ} \mathrm{C}\right)$. However, at $0.6 \% \mathrm{CF}$ was higher stiffness modulus compared unmodified PA.

- For the result dynamic creep, the existence of CF in PA pavement shows the significance reduction of strain value especially at $0.2 \% \mathrm{CF}$ content. It shows that the existence of $\mathrm{CF}$ can significantly enhance the permanent deformation resistance of PA.

- By overall performance tests, $0.6 \% \mathrm{CF}$ is the best proportion to be mixed with porous asphalt.

\section{ACKNOWLEDGMENT}

The support provided by the Malaysian Ministry of Higher Education and Universiti Malaysia Pahang in the form of a research grant (RDU/UMP) vote number RDU1803157 for this study is highly appreciated.

\section{REFERENCES}

[1] Ali, B. 2006. Numerical Model for The Mechanical Behaviour of Pavement: Application to the Analysis of Rutting. PhD Thesis, University of Science and Technology Lille, France.

[2] Liu Q, Cao D. 2009. Research on Material Composition and Performance of Porous Asphalt Pavement. Journal of Material in Civil Engineering, 21(4), pp. 135-140.

[3] Poulikakos, L.D., Partl, M.N. 2010. Investigation of Porous Asphalt Microstructure using Optical and Electron Microscopy. Journal of Microscopic, 240, pp. 145-154.

[4] McDaniel, R. 2015. Fiber Additives in Asphalt Mixtures, National Cooperative Highway Research Program.

[5] Satyanarayana, K.G., Arizzaga, G.G.C., Wypych, F. 2009 Biodegradable Composites based on Lignocellulosic Fibers - An Overview, Progress in Polymer Science, 34, pp. 982-1021.

[6] Jabatan Kerja Raya Malaysia (JKR). 2008. Standard Specification for Road Works, Section 4: Flexible Pavement. No. JKR/SPJ/2008-S4, pp S4-58-S4-69.

[7] Arshad, A.K., Masri, K.A., Ahmad, J., Samsudin, M.S. 2017. Dynamic Modulus of Nanosilica Modified Porous Asphalt, IOP Conference Series: Materials Science and Engineering, 271, 012008.

[8] Masri, K.A., Awang, H., Jaya, R.P., Ali, M.I., Ramli, N.I., Arshad, A.K. 2019. Moisture Susceptibility of Porous Asphalt Mixture with Nano Silica Modified Asphalt Binder. IOP Conference Series: Earth and Environmental Science. 244, 012028.

[9] Arshad, A. K., Masri, K. A., Ahmad, J., Samsudin, M. S., 2017. Investigation on Moisture Susceptibility and Rutting Resistance of Asphalt Mixtures incorporating Nanosilica Modified Binder. Pertanika Journal of Science and Technology, 25, pp. 19-30.

[10] Manosalvas-Paredes, M., Gallego, J., Saiz, L., Bermejjo, J.M. 2016. Rubber Modified Binders as an Alternative to Cellulose Fiber-SBS Polymers in Stone Matrix Asphalt. Construction and Building Material, 121, pp. 727-732.

[11] Masri, K. A., Arshad, A. K., Samsudin, M. S. 2016. Mechanical Properties of Porous Asphalt with Nanosilica Modified Binder. Jurnal Teknologi, 78: 7-2, pp. 139-146. 